\title{
Indian adaptation of the Cognistat : Psychometric properties of a cognitive screening tool for patients of traumatic brain injury
}

\author{
Ashum Gupta PhD, Natasha Khullar Kumar M Sc \\ Department of Psychology, University of Delhi, Delhi-110 007
}

\begin{abstract}
The present study was aimed at adapting the cognitive screening tool 'Cognistat' (Neurobehavioral Cognitive Status Exam) for use with the Indian community. As a part of the Indian adaptation of the test, the 'screen and metric' approach of assessment was eliminated. However, the screening item of the construction sub-test has been retained as a separate sub-test for evaluating immediate visual memory. Culturally irrelevant test items were identified under the, repetition, naming, memory, similarities and judgment sub-tests. Changes were made to these items on the basis of recommendation of 7 psychologists of Indian origin. The psychometric properties of the scale were evaluated in a sample of 30 patients with Traumatic Brain Injury (TBI) and 55 demographically matched healthy controls. The internal consistency of the test was high (Cronbach's alpha $=0.94)$. The test was found to have acceptable inter- rater and test-retest reliability. The concurrent validity of the test was established by comparing the performance of patients on MMSE and sub-tests of the Indian adaptation of Cognistat The test was found to have high discriminative validity as there was a significant difference in the performance of patients and controls on all subtests $(\mathrm{p}<.001)$. The adaptation of Cognistat provides the Indian population with a highly valuable cognitive screening tool.
\end{abstract}

Keywords: Cognistat, Indian Adaptation, Traumatic Brain Injury

\section{INTRODUCTION}

Several neurological, neurosurgical and psychiatric conditions are increasingly been recognized as being associated with cognitive and behavioral dysfunction ${ }^{1}$. Studies have indicated that severity of cognitive impairments is highly correlated to the long-term outcome and the level of functional independence a patient attains after brain injury ${ }^{2}$. Therefore, identification of cognitive deficits and appropriate application of this information is considered important for planning rehabilitation ${ }^{3}$. It is necessary to use a test that is a sensitive measure of several cognitive domains and can be administered in a short time span. For this purpose $^{4}$, advocate the use of standardized cognitive screening tools in clinical practice. Screening tools allow early detection of possible areas of cognitive deficits that can be further evaluated through more detailed neuropsychological tests.

\footnotetext{
Address for correspondence

Prof. (Ms.) Ashum Gupta

C-31 (29-31) Probyn Road

Delhi University Flats, Mall Road, Delhi

Ph:011- 2662278, 9871370107

E-mail : dr_ashumgupta@yahoo.com
}

Several cognitive screens are available and are being extensively used in evaluating cognition among different patient populations. However, it has been noted that no single cognitive screen is suitable for global use ${ }^{5}$. A cognitive screen must be validated for the patient population for which it is intended. A screening tool may only be considered effective if it is highly sensitive in correctly classifying individuals with and without cognitive deficit. In addition, the likelihood of a genuine cognitive impairment may only be inferred by comparing the patient's score to the performance of demographically matched controls.

The importance of examining the influence of ethnicity and race on cognitive testing has received an increased amount of focus over the past few years. Research has shown that there are reliable variations on most domains of cognition including verbal fluency, verbal and visual memory, motor ability, abstract reasoning and executive functioning that correlate with culture and ethnicity ${ }^{6,7}$. It has been found essential to consider cultural variations while evaluating cognition among patients having traumatic brain injury, stroke, various types of dementia and substance abuse ${ }^{8,9}$.

After a careful review of the existing Indian neuropsychological tests, no valid and reliable screening 
tool was found to be available that could effectively address the problems encountered by patients after traumatic brain injury (TBI). To meet this purpose, the Cognistat ${ }^{10,11}$ has been adapted for use with the Indian population. Research has demonstrated that Cognistat has high reliability and validity that make it an effective measure of cognition. The Cognistat has been designed as a 'cognitive screen' and is not intended as a substitute for full neuropsychological assessment. The Cognistat has been constructed on the theory that cognitive functions are discreet and can be assessed independently of each other using some specific tasks. Different subtests assess major domains of cognitive functioning namely, orientation, attention, language (further divided into spontaneous speech, comprehension, repetition, naming), construction, verbal memory, calculations, and reasoning (further divided into similarities and judgment). Through the use of this test it is possible to obtain a profile of the patient's cognitive strengths and weaknesses involving the key cognitive domains. This information would then guide the process of a detailed neuropsychological evaluation.

While the Mini-Mental State Exam (MMSE) ${ }^{12}$ is the most widely used instrument for assessing cognition among adults, it shows a high rate of false positives among individuals with low socioeconomic status and low education $^{13}$ and false negatives in mildly impaired persons ${ }^{14}$. In contrast, Roper et al ${ }^{15}$ found Cognistat effective in identifying cognitive deficits among $86 \%$ of the brain-injured patients as opposed to a success rate of $53 \%$ for MMSE. Researchers indicated that scoring each cognitive domain separately rather than having a global score (as the MMSE) makes Cognistat a more sensitive and efficient tool for identifying cognitive deficits $^{15}$.

Since its introduction, Cognistat has been applied to assessment of cognitive status in patients suffering from brain stroke ${ }^{16}$, dementia ${ }^{17}$, Parkinson's disease ${ }^{18}$, traumatic brain injury ${ }^{19}$, neuro-surgery ${ }^{20}$, encephalitis ${ }^{21}$, psychiatric illnesses ${ }^{22}$ and substance abuse ${ }^{23}$. Recently, the Cognistat has also been made available in a computerized version ${ }^{24}$.

In previous studies, the concurrent validity of Cognistat has been evaluated by comparing it to a number of standardized neuropsychological tests. Wallace et $\mathrm{al}^{25}$ paired the attention sub-test of the Cognistat with digit span sub-test from Wechsler Adult Intelligence Scale-
Revised $^{26}$ and the memory sub-test was paired with logical memory (II) from Wechsler Memory Scale- Revised ${ }^{27}$. Results showed that there was a significant relationship between patient's performance on the Cognistat and standardized neuropsychological tests. Nabors et al ${ }^{28}$ also found a significant relationship between Cognistat scores and neuropsychological measures such as California Verbal Learning Test ${ }^{29}$. The inter-rater reliability of the Cognistat has been found to be high with $r$ above $.90^{30}$. Keeping in mind these factors, the objective of the present research was to adapt the Cognistat for use with Indian community and to validate the instrument for use with patients having suffered from traumatic brain injury.

\section{INDIAN ADAPTATION OF COGNISTAT}

There are several differences in the administration, scoring procedure and content of the Indian adaptation of the Cognistat compared to the original. These changes have been made on the basis of recommendations of researchers who have evaluated various aspects of the Cognistat over the past several years. Following is a description of these modifications.

\section{ELIMINATION OF THE SCREEN AND METRIC APPROACH}

The Cognistat employs 'screen and metric method' of administration in which if a patient passes the screen item (which is a relatively difficult item presented at the beginning of a sub-test), they are considered to be intact in that domain of cognitive functioning and no further testing is carried out. If the patient fails the screen, the examiner administers the 'metric' (a series of graded questions that further clarify functioning in that domain). However, research has shown this method to yield a high frequency of false positives ${ }^{31,32}$. Researchers have also noted that the screen and metric approach lead to procedural variability by creating significant differences in the delay period involved in the recent memory subtest $^{31}$. Patients unable to pass the screen items, actually have more intervening distracter items and a longer absolute delay between presentation and recall of items on the memory sub-test. Similarly, Van Grop et al ${ }^{33}$ recommend the use of the metric items on the Cognistat in order to maximize the reliability. Keeping these factors in mind the screen items have been eliminated from the Indian adaptation of the Cognistat and all the items of the metric are administered to the participants. 


\section{SUB-TEST FOR EVALUATING IMMEDIATE VISUAL MEMORY}

Some researchers had noted that the screen items are not equivalent in nature to the metric items that follow in the Cognistat ${ }^{34}$. Perhaps the best example involves the Construction sub-test. While the metric is a block design task, the screen item is actually a measure of immediate visual memory. Researchers found a strong correlation between the verbal memory sub-test and construction sub-test ${ }^{34}$. They attributed this correlation to the memory component involved in this screen item. Cullen et $\mathrm{al}^{4}$ found that evaluating immediate visual memory is an important component of cognitive screening in their review of recent cognitive screening tests. Though the other screen items of the test have been eliminated the screening item of the constructional sub-test is retained as a separate sub-test labeled 'immediate visual memory'. This item aims to assess immediate visual memory, visual motor integration skills, fine motor skills and constructional praxis.

\section{DETAILED EVALUATION OF SPOKEN LANGUAGE}

A detailed assessment of the patient's language ability is an integral part of cognitive testing. An assessment of higher cognitive systems such as working memory and reasoning requires that the patient's language functions are intact ${ }^{35}$. While a systematic approach is required to test the various components of language, a careful analysis of the patient's spontaneous speech provides valuable information to the examiner ${ }^{36}$. The Cognistat contains 4 sub-tests for assessing the patient's language functions namely, spontaneous speech, comprehension, repetition and naming. While the comprehension, repetition and naming sub-test have a standardized scoring procedure, spontaneous speech is evaluated based on the qualitative judgment of the examiner. As a part of the Indian adaptation of the Cognistat, a checklist has been devised to serve as a guide for the examiner to assess various components of the patient's spontaneous speech (Table 1). This checklist contains a description of some of the common problems that may occur in spoken language due to brain lesions and provides for a step by step analysis of the patient's speech patterns $s^{36,37}$. According to Kay et $\mathrm{al}^{38}$, in evaluating a patient's speech the first step would be to rule out problems resulting from motor incoordination (speech apraxia) and motor weakness (dysarthria). Next, it is important to note whether the patient's speech is fluent or non-fluent and finally to assess the type of aphasic errors if any ${ }^{39}$. A 4-point rating system has been provided to help the examiner quantify the severity of the identified problem. According to this rating system, 3 indicates no deficit in a particular area of language while 0 indicates severe deficit. By carefully analyzing the results of all the 4 language sub-tests together the examiner would be able to diagnose various syndromes of language dysfunction such as Broca's and Wernick's aphasia.

Table 1: Checklist for evaluating spontaneous speech

\begin{tabular}{|c|c|c|}
\hline Speech disorder & Characteristics & $\begin{array}{l}\text { Severity } \\
(3,2,1,0)\end{array}$ \\
\hline Speech Apraxia & $\begin{array}{l}\text { The patient's speech is } \\
\text { incomprehensible because of } \\
\text { difficulty in articulation. This is } \\
\text { due to impairment in the } \\
\text { patient's ability to program the } \\
\text { positioning of speech } \\
\text { musculature and the sequencing } \\
\text { of muscle movements for the } \\
\text { volitional production of } \\
\text { phonemes. However, the patient } \\
\text { has no significant weakness, } \\
\text { slowness, or in-coordination in } \\
\text { reflex or automatic acts. }\end{array}$ & \\
\hline Dysarthria & $\begin{array}{l}\text { Disorder of the sensorimotor } \\
\text { performance of speech acts } \\
\text { characterized by disturbances in } \\
\text { speech musculature control due } \\
\text { to paresis, slowness, altered tone } \\
\text { or dyskinetic movements. }\end{array}$ & \\
\hline $\begin{array}{l}\text { Non-fluent } \\
\text { speech } \\
\text { (Dysfluency) }\end{array}$ & $\begin{array}{l}\text { Stuttering or stammering occurs. } \\
\text { Patient struggles with every word } \\
\text { and gives an impression of great } \\
\text { effort required for speech } \\
\text { production. }\end{array}$ & \\
\hline Anomia & $\begin{array}{l}\text { Word finding difficulty and } \\
\text { inability to name objects on } \\
\text { visual confrontation. Sponta- } \\
\text { neous speech is usually fluent } \\
\text { and grammatically rich but } \\
\text { contains many word finding } \\
\text { pauses and paraphasias of specific } \\
\text { object names. }\end{array}$ & \\
\hline Agrammatism & $\begin{array}{l}\text { Reduction of grammatical } \\
\text { elements in speech. }\end{array}$ & \\
\hline
\end{tabular}

Indian Journal of Neurotrauma (IJNT), Vol. 6, No. 2, 2009 


\begin{tabular}{|l|l|l|}
\hline $\begin{array}{l}\text { Paraphasias Phone- } \\
\text { mic Paraphasia }\end{array}$ & $\begin{array}{l}\text { Substitution, omission, addition } \\
\text { or perseveration of a phoneme } \\
\text { or error of phoneme sequence. } \\
\text { Substitution of a presumably } \\
\text { intended word with a meaning- } \\
\text { related one. }\end{array}$ & \\
\hline Verbal Paraphasia & $\begin{array}{l}\text { Substitution of a presumably } \\
\text { intended word with another } \\
\text { unrelated word. }\end{array}$ & $\begin{array}{l}\text { The recurrent production of a } \\
\text { previous response out of context }\end{array}$ \\
\hline Perseveration & $\begin{array}{l}\text { The repetitive and stereotyped } \\
\text { use of a communicatively } \\
\text { acceptable word or phrase } \\
\text { without prepositional meaning } \\
\text { (E.g. 'yes', 'my god', 'I don't } \\
\text { know' etc.). }\end{array}$ \\
\hline Stereotypy & $\begin{array}{l}\text { The automatic and compulsive } \\
\text { production of the same phrase, } \\
\text { word, neologism, syllable, or } \\
\text { sound contrary to intention }\end{array}$ & $\begin{array}{l}\text { Repetition of utterances of the } \\
\text { communication partner, } \\
\text { frequently with adequate } \\
\text { changes denoting the speaker } \\
\text { (E.g. 'How are you?'- } \\
\text { 'How am I?') }\end{array}$ \\
\hline Speech \\
Automatism
\end{tabular}

Scoring:

3 = No deficit; 2 = Mild deficit; 1 = Moderate deficit; $0=$ severe deficit

Any other speech disorder .

\section{CULTURE RELEVANT CHANGES IN THE TEST ITEMS}

A panel of 7 bilingual psychologists (with an average of 3 years of clinical work experience) was set up to evaluate the relevance of the items of the Cognistat to the Indian culture. They were asked to provide ratings on a 4-point Likert scale (with 4 indicating excellent relevance and 1 indicating no relevance). Items receiving mode ratings of 2/4 or lower were modified as these ratings indicated poor or no relevance. Keeping this criterion in mind, it was found that the orientation, attention, spontaneous speech, comprehension, construction and calculation sub-tests did not require any modifications (mode ratings 4/4: indicating excellent relevance; percentage of agreement: $100 \%$ ). However, some of the items on the repetition, naming, memory, similarities and judgment sub-tests received poor ratings in terms of their relevance and required modifications. The psychologists were asked to provide specific comments and suggestions for making these changes. The basic principal behind modifying a test item was to retain the difficulty level of the original item and to improve its relevance to the Indian context. On the repetition sub-test, 'The honeycomb drew a swarm of bees' was changed to 'Children are coming here from the park'. These changes were made keeping in mind opinions of a majority of the members of the panel.

Similarly, on the naming sub-test, the item 'horseshoe' was changed to 'weighing scales', 'anchor' was changed to 'ship', 'octopus' was changed to 'spider' and 'xylophone' was changed to 'flute'. Corresponding changes were made to the pictures presented in the stimulus booklet. All the pictures were approved by the panel of psychologists before being included in the final stimulus booklet. The memory sub-test involved changing two words, the word 'robin' was changed to 'hen' and 'piano' was changed to 'tabla' (a common Indian musical instrument). In the similarities sub-test, the item 'tulip' was replaced with 'lotus' (a more widely known flower), while 'corkscrew' was replaced with 'screwdriver'.

Modification was also made to the judgment sub-test item 1, as it was rated as having poor cultural relevance (mode ratings 1/4: indicating no relevance; percentage of agreement: $71 \%$ ), 'What would you do if you woke up one minute before 8 a.m. and remembered that you had an important appointment downtown at 8:00 o'clock?' was changed to 'What would you do if you woke up one minute before 8 a.m. and remembered that you had an important appointment somewhere far from your house at 8:00 o'clock?' A slight modification was also made to item 2 of the judgment sub-test, 'What would you do if while walking besides a lake you found that a two-yearold child was playing at the end of the pier?' was changed to 'What would you do if while walking beside a lake you saw that a two-year-old child was playing alone very close to the water?' These modifications were acceptable to $85 \%$ of members of the panel and were incorporated in the final test.

\section{METHOD}

\section{Participants}

The sample consisted of 55 healthy controls and 30 patients with moderate to severe Traumatic Brain Injury (TBI). All patients were in the post-acute stage of 

screening tool for patients of traumatic brain injury

recovery. The patients were recruited from the outpatient department of Vidyasagar Institute of Mental Health and Neurosciences (VIMHANS, New Delhi), a hospital specializing in treatment of psychiatric and neurological disorders. At the beginning of the assessment the examiner recorded the social and demographic details \& medical history of all the participants using a detailed proforma.

The patient's were included in the study based on the following criteria: (1) diagnosis of moderate to severe TBI (2) a minimum of 2 months elapsed since incidence of TBI (3) a GCS score of 15 at the time of inclusion into the study (4) a minimum of 12 years of school education and good pre-morbid fluency in English. Patients with global aphasia, quadriplegia, developmental disorders, history of psychiatric illness and substance abuse were excluded from the study. Patients and controls gave written informed consent for participating in the study and for video recording of the assessment session.

It is noteworthy that most of the patient's hospital discharge summaries had been poorly written and standardized assessment tools, like Glasgow Coma Scale ${ }^{40}$ had not been administered to patients at the time of admission or discharge. The severity of TBI has been defined on the basis of duration of Post Traumatic Amnesia (PTA) analyzed retrospectively on the basis of some of the hospital discharge summaries and family's report. The duration of PTA ranged from 1 hour to 7 days for all the patients and they were classified as having moderate to severe injuries on the basis of the criterion defined by Bigler ${ }^{41}$. Information regarding the duration of hospitalization after TBI and other clinical characteristics has been presented in Table 2 . The control group comprised of 26 (47.27\%) males and $29(52.73 \%)$ females with a mean age of 26.53 years $(S D=8.48)$. The average education of the control group was 14.67 years $(S D=3.09)$. In the control group, 23 participants were students, 15 worked as office clerical staff, 3 were employers, 2 were managers, 2 were professionals, 5 were housewives, 2 were dealers and 3 were unemployed. All participants of the control group were fluent in English.

\section{PROCEDURE}

The Indian adaptation of the Cognistat was individually administered to each of the participants recruited for the study. The test was administered to patients when they came to the hospital's out-patient department for periodical review with the consultant neurologist. It took 15-30 minutes to administer the test depending on the
Table 2 : Clinical characteristics of the TBI patients

\begin{tabular}{|c|c|c|c|c|c|}
\hline & Mean & SD & Range & $\mathbf{n}$ & $\%$ age \\
\hline $\begin{array}{c}\text { Gender - } \\
\text { Male } \\
\text { Female }\end{array}$ & & & & $\begin{array}{c}25 \\
5\end{array}$ & $\begin{array}{l}83.3 \\
16.7\end{array}$ \\
\hline Age (years) & 33.5 & 10.7 & $18-53$ & & \\
\hline Education (years) & 14.6 & 2.3 & $12-19$ & & \\
\hline $\begin{array}{l}\text { Employment situation } \\
\text { prior to brain injury } \\
\text { Students } \\
\text { Office clerical staff } \\
\text { Employers } \\
\text { Managers } \\
\text { Professionals } \\
\text { Dealers } \\
\text { Unemployed }\end{array}$ & & & & $\begin{array}{l}5 \\
7 \\
4 \\
2 \\
8 \\
3 \\
1\end{array}$ & $\begin{array}{c}16.7 \\
23.3 \\
13.7 \\
6.7 \\
26.7 \\
10.0 \\
3.3\end{array}$ \\
\hline $\begin{array}{l}\text { Cause of TBI } \\
\text { Road traffic accident } \\
\text { Fall } \\
\text { Gun shot }\end{array}$ & & & & $\begin{array}{c}22 \\
7 \\
1 \\
\end{array}$ & $\begin{array}{c}73.3 \\
23.3 \\
3.3 \\
\end{array}$ \\
\hline $\begin{array}{l}\text { Time elapsed since } \\
\text { injury (months) }\end{array}$ & 27.6 & 33.8 & $2-120$ & & \\
\hline $\begin{array}{l}\text { Post Traumatic } \\
\text { Amnesia (days) } \\
\begin{array}{c}1 \text { h-1 day } \\
1-7 \text { days }\end{array}\end{array}$ & & & & $\begin{array}{l}13 \\
17\end{array}$ & $\begin{array}{l}43.3 \\
56.7\end{array}$ \\
\hline $\begin{array}{l}\text { Duration of } \\
\text { hospitalization (days) }\end{array}$ & 28.1 & 19.8 & $10-90$ & & \\
\hline $\begin{array}{l}\text { Motor disability at the } \\
\text { time of assessment } \\
\text { Hemiplegia } \\
\text { Hemiparesis }\end{array}$ & & & & $\begin{array}{l}2 \\
5\end{array}$ & $\begin{array}{c}6.7 \\
16.7\end{array}$ \\
\hline
\end{tabular}

patient's comprehension and cooperation level. For evaluating the concurrent validity, all patients were administered the MMSE and Indian adaptation of the Cognistat in a counter balanced sequence. The test retest reliability was examined in a sample of $8 \mathrm{TBI}$ patients. The sub-tests were administered to the participants as per the sequence mentioned in Table 3.

\section{DATA ANALYSIS}

The psychometric properties of a scale determine in part the confidence the examiner can have in the results obtained from it. The critical psychometric properties of the Indian adaptation of the Cognistat have been evaluated using SPSS version 12 (SPSS Inc., Chicago, IL, USA). Based on the performance of patients, the 
Table 3 : Sub-tests of the Indian adaptation of Cognistat

\begin{tabular}{|c|c|c|}
\hline Sub-test & $\begin{array}{l}\text { No.o } \\
\text { item }\end{array}$ & Description \\
\hline Orientation & 9 & $\begin{array}{l}\text { Items require subjects to answer } \\
\text { questions on person, place and time. }\end{array}$ \\
\hline Attention & 8 & $\begin{array}{l}\text { Items require subjects to repeat a series } \\
\text { of three-to-six digits with two trials each. }\end{array}$ \\
\hline \multirow{2}{*}{\begin{tabular}{|l|} 
Language \\
a) Spontaneous \\
Speech
\end{tabular}} & & \\
\hline & 1 & $\begin{array}{l}\text { a) Evaluates the qualitative aspect of } \\
\text { spontaneous speech by asking the } \\
\text { patient to describe a picture. The } \\
\text { examiner records the observations } \\
\text { using spontaneous speech checklist. }\end{array}$ \\
\hline $\begin{array}{l}\text { b) Compre- } \\
\text { hension }\end{array}$ & 6 & $\begin{array}{l}\text { b) Items require subjects to follow } \\
\text { instructions and perform tasks with } \\
\text { increased step-by-step complexity. }\end{array}$ \\
\hline c) Repetition & 6 & $\begin{array}{l}\text { c) Items require subjects to repeat } \\
\text { complex sentences with increasing } \\
\text { difficulty in vocabulary, context and } \\
\text { length }\end{array}$ \\
\hline d) Naming & 8 & $\begin{array}{l}\text { d) Items require subjects to names } \\
\text { pictures of objects from the stimulus } \\
\text { booklet. }\end{array}$ \\
\hline \begin{tabular}{|l|} 
Immediate \\
Visual Memory
\end{tabular} & 1 & $\begin{array}{l}\text { Requires subjects to learn two abstract } \\
\text { designs from the stimulus booklet } \\
\text { within } 10 \text { seconds and immediately } \\
\text { draw both the designs from memory. }\end{array}$ \\
\hline $\begin{array}{l}\text { Constructional } \\
\text { Ability }\end{array}$ & 3 & $\begin{array}{l}\text { Items require subjects to use tokens to } \\
\text { construct block designs of increasing } \\
\text { complexity }\end{array}$ \\
\hline Verba & 4 & $\begin{array}{l}\text { Items require subjects to recall the four } \\
\text { words presented to them after the } \\
\text { Attention sub-test, whilst other sub- } \\
\text { tests serve as interference for delayed } \\
\text { recall }\end{array}$ \\
\hline Calculation & 4 & $\begin{array}{l}\text { Items involve completing mathematical } \\
\text { problems orally including addition (two } \\
\text { items) subtraction and division }\end{array}$ \\
\hline Reasoning & & \\
\hline a) Similarities & 4 & $\begin{array}{l}\text { a) Items ask subjects to state how pairs } \\
\text { of items are alike with increasing levels } \\
\text { of abstract concept formation } \\
\text { required for each successive item }\end{array}$ \\
\hline b) Judgment & 3 & $\begin{array}{l}\text { b) Items require subjects to solve } \\
\text { hypothetical problems related to } \\
\text { everyday experience. }\end{array}$ \\
\hline
\end{tabular}

Indian Journal of Neurotrauma (IJNT), Vol. 6, No. 2, 2009 reliability was examined with an assessment of internal consistency using Cronbach's alpha coefficient. Test-retest reliability and inter-rater reliability were examined using intra-class correlation coefficients. Pearson's $r$ was used to assess the correlation between patient's performance on the MMSE and Indian adaptation of Cognistat in order to establish the concurrent validity. Further, the discriminative validity was examined by comparing patients and control group using multi-variate analysis of variance (MANOVA) and t-test.

\section{RESULTS}

\section{Internal consistency}

The Indian adaptation of the Cognistat showed high internal consistency as measured by the Cronbach's alpha (.94). The Cronbach's alpha for the major sub-tests are as follows: orientation .87 , attention .69 , comprehension .79 , repetition .71 , naming .80 , construction .78 , memory .89 , calculation .68 , similarities .69 and judgment .61. The internal consistency for the immediate visual memory sub-test could not be calculated as it contains only one item.

\section{Test -retest reliability}

The test retest reliability of the Indian adaptation of Cognistat was evaluated by testing 8 patients from the sample on two separate visits to the hospital for follow up with consultant neurologists. Of the remaining 22 patients, 12 were enrolled in neuropsychological rehabilitation programs after the initial assessment and 10 patients dropped out of the study. The interval between testing ranged from 15 days to 30 days with a mean retest interval of 20.88 days $(S D=6.01)$. Table 4 shows the test retest reliability coefficients examined using intraclass correlation. The test retest reliability coefficients for 10 of the 11 sub-tests show adequate stability of scores over time. Poor intra-class correlation was found between the two administrations of the judgment sub-test. This maybe attributed to the restricted range of scores obtained by the patient in the second testing $(S D=.35)$.

\section{Inter- rater reliability}

In order to evaluate the inter scorer reliability, protocols from 10 patients were randomly selected from the sample of TBI patients and two independent scorers rated the performance of the patients. Both the scores held doctoral degrees in clinical psychology. The entire process of administration was video recorded for these 10 patients. The video recordings and the record forms were made 
Table 4 : Test- retest reliability coefficients

\begin{tabular}{|l|c|c|c|c|c|}
\hline \multirow{2}{*}{ Sub-tests } & \multicolumn{2}{|l|}{ 1st testing } & \multicolumn{2}{|c|}{ 2nd testing } & Intra-class \\
\cline { 2 - 5 } & Mean & SD & Mean & SD & correlation \\
\hline Orientation & 8.75 & 3.62 & 8.75 & 2.92 & 0.97 \\
\hline Attention & 5.13 & 1.96 & 5.25 & 1.49 & 0.93 \\
\hline Comprehension & 4.50 & 1.60 & 4.75 & 1.04 & 0.92 \\
\hline Repetition & 8.50 & 3.51 & 8.88 & 3.31 & 0.99 \\
\hline Naming & 6.00 & 2.33 & 6.00 & 2.33 & 1.00 \\
\hline $\begin{array}{l}\text { Immediate } \\
\text { visual memory }\end{array}$ & 1.25 & 0.71 & 1.38 & 0.52 & 0.91 \\
\hline Construction & 2.38 & 2.13 & 2.50 & 1.41 & 0.89 \\
\hline Memory & 6.63 & 3.78 & 6.63 & 3.78 & 0.98 \\
\hline Calculations & 3.25 & 0.89 & 3.25 & 0.71 & 0.87 \\
\hline Similarity & 3.50 & 2.39 & 4.00 & 2.00 & 0.96 \\
\hline Judgment & 3.63 & 0.92 & 3.87 & 0.35 & 0.31 \\
\hline
\end{tabular}

available to both the scores. The intra-class correlation coefficient for the orientation, attention, comprehension, repetition, naming, immediate visual memory, construction, memory and calculations sub-test was 1.00. The intra-class correlation coefficient for similarities subtest was .82 while the intra-class correlation coefficient for the judgment sub-test was .95 . Results indicate a high inter-rater reliability of the Indian adaptation of Cognistat.

\section{Concurrent validity}

Since the Cognistat does not have a composite or global score like the MMSE, the patient's performance on subtests of the Cognistat were compared with specific items of the MMSE that measure the same underlying cognitive function. Using the Pearson's $r$ a significant correlation was found between the tests on dimensions of orientation to time $(r=.94 ; \mathrm{p}<.01)$; orientation to place $(\mathrm{r}=.46$; $\mathrm{p}<.05)$; attention $(\mathrm{r}=.58 ; \mathrm{p}<.01)$; naming $(\mathrm{r}=.86$; $\mathrm{p}<.01)$; repetition $(\mathrm{r}=.56 ; \mathrm{p}<.01)$ and comprehension $(\mathrm{r}=.95 ; \mathrm{p}<.01)$. No significant correlation was found between the calculation sub-test of the Cognistat and mental balance item of the MMSE $(r=-.09)$. The correlation between the memory sub-test of the Cognistat and MMSE was not assessed as the interval of delay in recall is not comparable in the two tests.

\section{Discriminative validity}

The performance of patients and the control group were compared using multi-variate analysis of variance
(MANOVA). The MANOVA revealed a statistically significant group effect on the subject's performance on the Indian adaptation of Cognistat (Pillai Bartlett trace: $F(11,73)=9.42, p<0.001)$. Using the t-test, statistically significant differences were found between the patient and control group on all sub-tests. The results of t-tests are presented in table 5 .

\section{DISCUSSION}

The present study was undertaken with the aim of adapting the cognitive screening tool 'Cognistat' for use with the Indian community. The test has been validated for use with patients having suffered from moderate to severe TBI. Items of the Cognistat were adapted for use with the Indian population with great care. On the basis of recommendations of an expert panel of bilingual psychologists, changes were made in the repetition, naming, memory, similarities and judgment sub-tests to increase their cultural relevance. Our results are similar to Chan et $\mathrm{al}^{42}$, who also found culturally non-relevant items in the same sub-tests while developing the Chinese adaptation of the test.

Using the Cronbach's alpha, the internal consistency of all sub-tests combined was very high with a coefficient of .94. The reliability for orientation, comprehension, naming, construction and memory sub-tests appear to be satisfactory as researchers claim that Cronbach's alpha coefficients ranging between .78 and .88 indicate acceptable to high reliability ${ }^{43}$. The alpha coefficient of

Table 5 : Comparison of Cognistat profile between control group and patients with brain-injury

\begin{tabular}{|c|c|c|c|c|c|c|}
\hline \multirow[b]{2}{*}{ Sub-tests } & \multicolumn{2}{|c|}{$\begin{array}{l}\text { Patients with } \\
\text { Brain Injury } \\
(\mathbf{n}=30)\end{array}$} & \multicolumn{2}{|c|}{$\begin{array}{l}\text { Controls } \\
\text { Cognistat } \\
(\mathbf{n}=55)\end{array}$} & \multirow[b]{2}{*}{$t$} & \multirow[b]{2}{*}{ p-values } \\
\hline & $\mathrm{M}$ & SD & $\mathrm{M}$ & SD & & \\
\hline Orientation & 9.47 & 3.54 & 11.93 & 0.26 & 5.14 & $<0.001^{* *}$ \\
\hline Attention & 5.47 & 1.68 & 6.93 & 1.21 & 4.61 & $<0.001^{* *}$ \\
\hline Comprehension & 4.83 & 1.51 & 5.84 & 0.42 & 4.62 & $<0.001^{* *}$ \\
\hline Repetition & 10.00 & 2.17 & 11.45 & 1.09 & 4.13 & $<0.001^{* *}$ \\
\hline Naming & 6.20 & 2.11 & 7.75 & 0.55 & 5.14 & $<0.001^{* *}$ \\
\hline $\begin{array}{l}\text { Immediate } \\
\text { visual memory }\end{array}$ & 1.20 & 0.76 & 1.87 & 0.34 & 5.64 & $<0.001^{* *}$ \\
\hline Construction & 2.13 & 1.94 & 4.91 & 1.28 & 7.91 & $<0.001^{* *}$ \\
\hline Memory & 7.03 & 3.66 & 11.07 & 1.61 & 7.05 & $<0.001^{* *}$ \\
\hline Calculations & 3.20 & 1.10 & 3.84 & 0.37 & 3.92 & $0.004^{*}$ \\
\hline Similarity & 4.33 & 2.12 & 7.16 & 1.15 & 7.99 & $<0.001^{* *}$ \\
\hline Judgment & 3.63 & 1.59 & 5.13 & 1.02 & 5.27 & $<0.001^{* *}$ \\
\hline
\end{tabular}

Indian Journal of Neurotrauma (IJNT), Vol. 6, No. 2, 2009 
the attention, repetition, calculation, similarities and judgment sub-tests ranged from .61-.71 and could be considered borderline. However, alpha coefficient of this size is not necessarily an obstacle in using a sub-test ${ }^{44}$. As mentioned earlier, the internal consistency for the immediate memory sub-test could not be calculated as this sub-test contains only 1 item.

Results showed that 10 of the 11 sub-tests of the Indian adaptation of the Cognistat had high test retest reliability over a period of 15-30 days. However, there was a low correlation between scores obtained by patients in the first and second testing on the judgment sub-test. It is important to note that the mean score obtained by the patients on the two testing sessions did not differ much, but the range of scores obtained by the patients on the second testing were very restricted as indicated by a SD of .35. Restricted ranges of scores are known to produce spuriously low test-retest coefficients as reliability estimates are affected by the distribution of scores $^{45,46}$. Similar results were obtained by Louge et $\mathrm{al}^{34}$ as they could not make a valid measurement of the test-retest reliability of many of the sub-test of Cognistat due to a very restricted range of scores obtained in sample of psychiatric patients.

The concurrent validity was evaluated by comparing patient's performance on items of the MMSE to subtests of the Cognistat. The correlation was found to be high for 6 of the 7 cognitive constructs compared. No correlation was found between patient's performance on mental balance item of the MMSE and calculation subtest of the Cognistat. The mental balance item of the MMSE requires the patient to sequentially subtract 7 from a given number without repetition of instructions, while the Cognistat requires the patient to perform single step calculations where instructions can be repeated on the patient's request. A much higher loading of working memory in the mental balance item of the MMSE than in the calculation sub-test of the Cognistat could have led to a poor correlation between the patient's performance on these items.

The discriminative validity of the test was examined by comparing the performance of patients with TBI to demographically matched controls. The patient group was found to have significantly poorer performance on all the sub-tests compared to the control group ( $\mathrm{p}<.001)$. Overall, results indicate that the Indian adaptation of the Cognistat has a higher discriminative validity than the Chinese adaptation ${ }^{42}$ in which only 6 out of 10 subtests showed significant difference in the performance controls and a sample of 53 stroke patients with a mean age of 69.5 years. The results of the present study find support from Nabors et $\mathrm{al}^{28}$ who have shown the high efficacy of Cognistat in identifying cognitive deficits among patients of TBI in western countries.

It is important to note that there was a significant difference between the performance of patients and controls on immediate visual memory sub-test $(\mathrm{p}<.001)$. These results are similar to Schrimsher et $\mathrm{al}^{47}$ who also found a high rate of failure on this task among patients with history of substance abuse. The immediate visual memory sub-test was also found to have a high interrater and test re-test reliability. These results justify the inclusion of the immediate visual memory sub-test as a part of the Indian adaptation of Cognistat.

The study is also an indicator of the high prevalence of cognitive deficits in patients post TBI. Statistics in India show that 1, 25,000 persons get disabled because of TBI every year ${ }^{48}$. Studies have shown that $5-18 \%$ of the patients suffering from TBI many continue to suffer from severe physical and cognitive disability even 6 months post injury ${ }^{49}$. The Indian adaptation of Cognistat represents a feasible option for cognitive assessment where time, training and materials are at a premium and the critical question is whether or not a cognitive deficit is present. It is hoped that the availability of such a cognitive screening tool would lead to early identification of cognitive deficits among patients and appropriate referrals would be made for neuropsychological rehabilitation.

\section{CONCLUSION}

In future work it would be necessary to assess the efficacy of the Indian adaptation of the Cognistat in evaluating cognition among patients with different medical diagnosis such as stroke, herpes encephalitis, epilepsy, dementia, psychiatric disorders and substance abuse. It would also be necessary to translate the Indian adaptation of the Cognistat to different languages and dialects spoken in India and generate normative data for individuals differing in age and education. In the present study, the sample size was very small and the study needs to be replicated in a larger group of patients. It also must be noted that there may be a doubt regarding the homogeneity of the patient group given that GCS scores at the time of injury were not available for most of the patient's the severity of injury had to be determined retrospectively on the basis of duration of PTA. Despite 
these limitations, the results of the present study indicate that the Indian adaptation of the Cognistat is reliable and valid instrument for evaluating cognitive deficits among patients of TBI. The results of the study justify the utilization of this tool in clinical settings for screening patients for potential cognitive deficits.

\section{REFERENCES}

1. Turner-Strokes L. (Ed.). Royal College of Physician and British Society of Rehabilitation. Medicine. Rehabilitation following acquired brain injury: National Clinical Guidelines. London. RCP, BSRM. (2003).

2. Tatemichi, TK, Desmond DW, Stern Y, Paik M, Sano M, Bagiella E. Cognitive impairment after stroke: Frequency, pattern and relationship to functional abilities. J Neurol Neurosurg Psychiat 1994;57:202-7.

3. Moroney JT, Desmond DW. Cognitive impairment and risk of stroke in the older population: Comment. J Amer Geriatric Soc 1996; 44: 1401-11.

4. Cullen B, O’ Neill B, Evans JJ, Coen RF, Lawlor BA. A review of screening tests for cognitive impairment. J Neurol Neurosurg Psychiat 2007; 78: 770-99.

5. Brodaty H, Clarke J, Ganguli M, Grek A, Jorm AF, Khachaturian Z, Scherr P. Screening for cognitive impairment in general practice: toward a consensus. Alzheimer Dis Assoc Disord 1998; 12: 1-13.

6. Jacobs DM, Sano M, Albert S, Schofield P, Dooneief G, Stern Y. Cross-cultural neuropsychological assessment: A comparison of randomly selected, demographically matched cohorts of English- and Spanish-speaking older adults. J Intl Neuropsychol Soc 1997; 4: 531-8.

7. Manly JJ, Miller SW, Heaton RK, et al The effect of AfricanAmerican acculturation on neuropsychological test performance in normal and HIV-positive individuals. J Intl Neuropsychol Soc 1998; 5: 291-302.

8. Horton AM Jr., Roberts C. Derived trail making test indices in a sample of heroin abusers: demographic effects. Intl J Neurosc 2002; 112: 225-34.

9. Lichtenberg PA, Ross TP, Youngblade L, Vagel SJ. Normative Studies Research Project Test Battery: Detection of dementia in African American and European American urban elderly patients.

The Clinical Neuropsychologist 1998; 12: 146-54.

10. Kiernan R J, Mueller J, Langston J W, Van Dyke C. The Neurobehavioral Cognitive Status Examination: A brief but quantitative approach to cognitive assessment. Ann Int Med 1987; 107: 481-5.

11. Northern California Neurobehavioral Group. Cognistat: The Neurobehavioral Cognitive Status Examination in older psychiatric population. Fairfax CA: The Northern California Neurobehavioral Group. (1995).
12. Folstein M F, Folstein SE, Mchigh PR. 'Mini-mental state': A practical method for grading the cognitive status for outpatients for the clinician. J Psychiat Res 1975; 12: 189-98.

13. Fountoulakis KN, Tsolaki M, Mohs RC, Kazis A. Epidemiological dementia index: a screening instrument for Alzheimer's disease and other types of dementia suitable for use in populations with low education level.

Dementia and Geriatric Cognitive Disorders 1998; 9: 329-38.

14. Sabe L, Jason L, Juejati M. Sensitivity and specificity of the Mini- Mental State Exam in the diagnosis of dementia. Behavioral Neurol 1993; 6: 207-10.

15. Roper B, Bieliauskas LA, Peterson MR. Validity of the MiniMental State Examination and the Neurobehavioral Cognitive Status Examination in cognitive screening.

Neuropsychiat Neuropsychol Behavioral Neurol 1996; 9: 54-7.

16. Man DWK, Tam SF, Chan CH. Prediction of functional rehabilitation outcomes in clients with stroke. Brain Injury 2006; 20: 205-11.

17. Salmon DP, Lange KL. Cognitive Screening and Neuropsychological assessment in early Alzheimer's disease. Clin Ger Med 2001; 17:229-54.

18. Margolin DI, Pate DS, Cox KS. The Neurobehavioral Cognitive Status Examination in probably Alzheimer's disease and Parkinson's Disease. (1991). Proceedings of the Meeting of the American Neurological Association (Seattle, WA).

19. Doninger NA, Heinemann AW, Bode RK, Sokol K, Corrigan JD, Moore D. Predicting community integration following traumatic brain injury with health and cognitive status measures.

Rehab Psychol 2003; 45:67-76.

20. Cammermeyer M, Pendergasst V. Profiles of cognitive functioning in subjects with neurological disorders. J Neuroscience Nursing 1997; 29: 163-9.

21. Moorthi S, Schneider WN, Dombvoy ML. Rehabilitation outcomes in encephalitis a retrospective study. Brain injury 1999; 12: 139- 46.

22. Fladby T, Schuster M, Gronli O, Sioholm H, Loeth S, Sexton H. Organic brain disease in psychogeriatric patients: impact of symptoms and screening methods on the diagnostic process.

J Geriat Psychiat Neurol 1999;12:16-20.

23. Zinn S, Bosworth HB, Edwards CL, Logue PE, Swartzwelder HS. Performance of recently detoxified patients with alcoholism on a neuropsychological screening test. Addictive Behaviors 2003; 28: 837-49.

24. Kong C, Man DWK, Tam SF. A comparison of conventional and computerized version of neurobehavioural cognitive status examination (NCSE) for persons with brain injury - a pilot study.

Brain Injury 2005; 19: 55. '(Abstracts)'

Indian Journal of Neurotrauma (IJNT), Vol. 6, No. 2, 2009 
25. Wallace JJ, Caroselli JS, Scheible RS, High WM Jr. Predictive validity of the Neurobehavioural Cognitive Status Examination (NCSE) in a post-acute rehabilitation setting. Brain Injury 2000; 14:63-9.

26. Wechsler D. Manual for the Wechsler Adult Intelligence ScaleRevised, New York: The Psychological Corporation (1981).

27. Wechsler D. Manual for the Wechsler Memory Scale-Revised, New York: The Psychological Corporation (1987).

28. Nabors NA, Millis SR, Rosenthal M. Use of the Neurobehavioral Cognitive Status Examination (Cognistat) in traumatic brain injury.

J Head Tr Rehab 1997; 12: 79-84.

29. Delis DC, Kramer JH, Kaplan E, Ober BA. The Manual for the California Verbal Learning Test-Adult Version. San Antonio, Tx: The Psychological Corporation (1987).

30. Mitrushina M, Abara J, Blumenfeld A. The neurobehavioral cognitive status examination as a screening tool for organicity in psychiatric patients.

Hospital and Community Psychiatry 1987; 45: 252- 6.

31. Drane DL, Osato SS. Using the neurobehavioral cognitive status examination as a screening measure for older adults. Arch Clin Neuropsychol 1997; 12: 139- 43.

32. Oehlert ME, Hass SD, Freeman MR, Williams MD, Ryan JJ, Sumerall SW. The Neurobehavioral Cognitive Status Examination: accuracy of the "screen-metric" approach in a clinical sample.

J Clin Psychol 1997; 53: 733-7.

33. Van Gorp W G, Marcotte T D, Sultzer D, Hinkin C, Mahler $\mathrm{M}$, Cummings J. Screening for dementia: comparison of three commonly used instruments.

J Clin Exp Neuropsychol 1999; 21: 29-38.

34. Logue PE, Tupler LA, D’Amico C, Schmitt FA. The Neurobehavioral Cognitive Status Examination: Psychometric properties in use with psychiatric inpatients. J Clin Psychol 1993; 49: 80-9.

35. Lezak MD. Neuropsychological Assessment 3rd edition. New York: Oxford University Press. (1995).

36. Strub RL, Black FW. The Mental Status Examination in Neurology, $4^{\text {th }}$ edition. Philadelphia. F.A. Davis Company (2000).
37. Wallesch CW, Horbach HJ, Blanken G. The assessment of acquired spoken language disorders. In P. Halligan, U. Kischka and J.C. Marshall (eds) Handbook of Clinical Neuropsychology. Oxford: Oxford University Press (2003).

38. Kay J, Lesser R, Coltheart M. Psycholinguistic Assessments of Language Processing in Aphasia (PALPA). Hove: Erlbaum. (1992).

39. Spreen O, Risser AH. Assessment of Aphasia. New York: Oxford University Press (2003).

40. Teasdale G, Jennett B. Assessment of coma and impaired consciousness. A practical scale. Lancet 1974; 13;2(7872):814.

41. Bigler E. Diagnostic clinical neuropsychology. Austin: University of Texas Press. (1984).

42. Chan CCH, Lee T, Fong KNK, Lee C, Wong V. (2002). Cognitive profile for Chinese patients with stroke. Brain Injury 2002;16: 873-84.

43. Gray-Little B, Williams VSL, Hancock TD. An item response theory analysis of Rosenberg Self-Esteem Scale. Personality and Social Psychology Bulletin 1997; 23: 443-51.

44. Schmitt N. Uses and abuses of coefficient alpha. Psychological Assessment 1996; 4:350-3.

45. Anastasi A. Psychological testing (6th ed.). New York: Macmillan Publishing Co., Inc. (1988).

46. McCall RB. Fundamental statistics for behavior sciences. (6th ed.). New York: Harcourt Brace College Publishers (1994).

47. Schrimsher GW, O’Bryant SE, Parker JD, Burke RM. The relation between ethnicity and Cognistat performance in males seeking substance use disorder treatment. J Clin Expl Neuropsychol 2005; 27: 873-85.

48. Sudarsanan S, Chaudhry S, Pawar AA, Srivastava K. Psychiatric effects of Traumatic Brain Injury. Medical Journal of Armed Forces India 2007; 62: 259-63.

49. Sankla SK, Mishra M, Ansman JI. Think First. Neuorotrauma '98. Proceedings of Seventh National Neurotrauma Conference, Indore (1998). 